\title{
Musical applications of real-time signal processing
}

\author{
Jyri Pakarinen ${ }^{1 *}$, Jonathan S Abel $^{2}$, Federico Fontana ${ }^{3}$, Victor Lazzarini ${ }^{4}$ and Vesa Välimäki ${ }^{1}$
}

With the advent of digital technology, musical signal processing applications have greatly expanded the frontiers of artistic expression by creating a myriad of new possibilities for music and sound creation and manipulation, as well as music listening. The latest academic and commercial research has produced an abundant set of real-time signal processing applications for sound synthesis and control, realistic emulation of analog and vintage effects devices and synthesizers, musical content analysis, and audio coding. This special issue presents several new research results in musical real-time signal processing.

The issue starts with a review article by the guest editors, discussing recent advances in this fascinating field, focusing primarily on musical effects processing, synthesis, and virtual analog models. Novel sound synthesis algorithms are introduced in the following three research articles. In the first contributed research article "Trombone Synthesis by Model and Measurement", Smyth and Scott propose a physics-based trombone synthesis model making use of two transfer functions, which are measured inside and outside the instrument. In "Feedback Amplitude Modulation Synthesis" by Kleimola et al., the authors recast feedback amplitude modulation (FBAM) into the algebra of periodically linear time-varying digital filters. The third article "DiscreteTime Modelling of the Moog Sawtooth Oscillator Waveform", by Pekonen et al., challenges the mainstream trend in electronic musical circuit simulation based on virtual analog system modeling, by proposing a signal-based approach to the simulation of the Moog synthesizer oscillator waveforms.

Three other articles in this special issue discuss virtual analog modeling. In the article "Real-Time Guitar Preamp Simulation Using Modified Blockwise Method and Approximations", Macak and Schimmel address the

\footnotetext{
* Correspondence: jyri.pakarinen@gmail.com

${ }^{1}$ Department of Signal Processing and Acoustics, Aalto University School of Electrical Engineering, 02150 Espoo, Finland

Full list of author information is available at the end of the article
}

modeling of a guitar tube preamplifier by approximating solutions of differential equations using pre-computed multidimensional lookup-tables. The article "Real-time audio transformer emulation for virtual tube amplifiers", by Paiva et al., focuses on magnetics modeling, using wave digital filters to simulate the transformer located between the power amplifier and loudspeaker in a typical instrument tube amplifier setting. Parker, in "Efficient Dispersion Generation Structures for Spring Reverb Emulation", elaborates on a recent parametric filter model of electro-mechanical spring reverberation, in an aim to reduce its computational cost without sacrificing on model accuracy.

In addition to synthesis and audio effects, sound analysis plays an important role in real-time musical signal processing. This topic is crucial for example in developing interactive systems that could play live music together with human performers, and it is discussed in four research articles in this issue. In "Adaptive Linear Prediction filtering in DWT domain for Real-Time Musical Onset Detection", Gabrielli et al. contribute in the long established research on musical onset detection, by putting the accent on the efficiency, scalability, and programmability on current digital signal processing architectures. In their novel algorithm, accuracy is achieved at an affordable computational cost.

Glover et al. provide a further contribution to the onset detection research in the article "Real-Time Detection of Musical Onsets with Linear Prediction and Sinusoidal Modelling", which reviews some of the commonly used techniques for onset detection and proposes improvements using linear prediction. Furthermore, a new real-time detector employing additive synthesis is proposed. The article "Real-Time Recognition of Percussive Sounds by a Model-Based Method" by Şimşekli et al. proposes a new approach for on-the-fly detection of various types of percussion instruments. Musical interactivity is also central to the topic of the article "RealTime Audio-to-Score Alignment Using Particle Filter for Co-player Music Robots" by Otsuka et al. Here, the 
authors are interested in providing means for robot performers to find their way round a musical score, keeping in synchronization with other players.

The final article is related to low-bit rate audio coding. In "AVS-M Audio: Algorithm and Implementation", Zhang et al. review the new Chinese audio coding standard, which has similarities to other mobile audio coding techniques.

The articles received for this special issue clearly indicate that musical real-time signal processing is a blooming area of research with a lot of potential for successful commercial applications. We sincerely hope that you will find this special issue inspiring and useful in your work on musical real-time signal processing. We would like to thank the reviewers for their invaluable help in article selection, the technical staff of Hindawi Publishing Corporation, and of course all the authors for their contribution to this special issue.

\section{Author details}

${ }^{1}$ Department of Signal Processing and Acoustics, Aalto University School of Electrical Engineering, 02150 Espoo, Finland ${ }^{2}$ CCRMA, Stanford University,

Stanford, CA 94305-8180, USA ${ }^{3}$ Department of Mathematics and Computer Science, University of Udine, 33100 Udine, Italy ${ }^{4}$ Sound and Music

Technology Research Group, National University of Ireland, Maynooth, Ireland

Received: 28 August 2011 Accepted: 22 November 2011

Published: 22 November 2011

doi:10.1186/1687-6180-2011-108

Cite this article as: Pakarinen et al:: Musical applications of real-time signal processing. EURASIP Journal on Advances in Signal Processing 2011 2011:108.

\section{Submit your manuscript to a SpringerOpen ${ }^{\circ}$ journal and benefit from:}

- Convenient online submission

- Rigorous peer review

- Immediate publication on acceptance

- Open access: articles freely available online

- High visibility within the field

- Retaining the copyright to your article

Submit your next manuscript at $>$ springeropen.com 